IOS Press

\title{
Editorial
}

\section{Safe and effective medication utilization in pediatric patients requiring rehabilitation services during the Coronavirus pandemic of 2019}

\author{
Matthew McLaughlin \\ Children's Mercy - Kansas City, 2401 Gillham Road, Kansas City, MO 64108, USA \\ Tel.: +1 816234 3970; E-mail: mjmclaughlin@cmh.edu
}

\begin{abstract}
The role of pediatric rehabilitation providers during the Coronavirus Disease 2019 (COVID) pandemic of 2020 highlighted the need for improved knowledge about medications utilized in pediatric patients. Pediatric patients with cerebral palsy who were previously receiving botulinum toxin injections on a regular basis went prolonged periods of time between injections, and patients who have intrathecal baclofen pumps were called in to get refills with different intervals. The medically complex patients treated by rehabilitation providers were limited in the type and scope of care they received, and some may have developed adverse outcomes related to this delay in care. As a Pediatric Physiatrist who has advanced training and significant research experience within the realm of Clinical Pharmacology, I have seen this pandemic demonstrate the Sisyphean challenge of continuing appropriate tone management in patients with cerebral palsy while ensuring those patients with neuromuscular conditions maintain their highest level of function. Both of these clinical problems received significant attention within this issue, which I hope allows providers taking care of these populations a reference point to take to the bedside.
\end{abstract}

Keywords: Pediatrics, rehabilitation, COVID-19

\section{Introduction}

The general public is seeing the difficulty of bringing just one medication to market to fight the Coronavirus Disease 2019 (COVID-19). After initial shutdowns of schools and hospitals furloughing staff to decrease patient encounters, the United States has started to open up again; however, it is doing so without a proven cure for COVID-19. Several promising attempts have been made during the pandemic.

Medications that have been repurposed to try to limit the disease burden have been proposed, such as hydroxychloroquine for those who have had close contact with known persons infected with COVID-19 [1]. The Food and Drug Administration (FDA) initially is- sued an Emergency Use Authorization (EUA) for this medication in March of 2020, which allows medication housed within the Strategic National Stockpile to be used to treat patients with COVID-19; however, this was then rescinded in June, and the Centers for Disease Control and Prevention (CDC) subsequently recommended against the use of this medication in this manner [2]. Despite the initial public and political attention to this medication, statistically it performed no better than placebo in preventing COVID-19 transmission [1]. Physicians reacted strongly to this as a potential treatment, and hydroxychloroquine and chloroquine prescribing increased 80 -fold by "Non-routine prescribers" when comparing the number of new prescriptions in March of 2020 to the same time period 
in 2019 [2]. The rate of prescriptions for this medication increased by 'Routine prescribers', 'Primary care prescribers', and 'Non-routine prescribers' during the study period. Naturally, several specialties commonly treating pediatric patients in need of rehabilitation (i.e., Physical Medicine and Rehabilitation, Neurology, Neurosurgery, and Orthopedic Surgery) were listed amongst the specialties that were considered 'Non-routine prescribers.' [2].

Other attempts for treating patients with COVID-19 have been more promising. For instance, remdesivir has decreased the median time to recovery by approximately 5 days [3]. It has also been shown to work against SARS-CoV-1 and the Middle East respiratory syndrome (MERS-CoV) viruses [4-6]. Remdesivir is thought to be able to inhibit COVID-19 (SARS-CoV-2) in vitro. Along with dexamethasone, which has been shown to improve respiratory function in mechanically ventilated, severely affected patients [7], remdesivir appears to have risen to the top of list of medications with more data behind its use.

Despite the promise of remdesivir, the race to be the first vaccine approved by the FDA in the United States remains a potentially lucrative and life-saving venture. Operation Warp Speed is a government sponsored partnership with the pharmaceutical industry to produce 300 million safe, effective doses of COVID19 vaccine by January 2021. Significant partnerships have been formed between the Department of Health and Human Services, the CDC, the National Institute of Health, the Biomedical Advanced Research and Development Authority, and the Department of Defense. Together, 10 billion dollars have been committed to this project [8]. For the first time, the cost of Research and Development (R\&D) to develop a de novo medication or vaccination is extremely transparent and much more mainstream than in recent history. The current average cost to bring one therapeutic medication to market is 1.3 billion dollars (United States dollars), which is actually lower than prior studies that have placed this amount closer to 2.8 billion [9]. Furthermore, some of these studies do not cover the cost of R\&D for therapeutics that do not make it to market and fail prior to being released to the general public.

Historically, pediatric patients have missed out on many therapeutics designed to treat specific conditions and may be missing out on the development of vaccines and medications for treatment of COVID-19. In 1997, the FDA established a Pediatric Exclusivity program through the Food and Drug Administration Modernization Act, which has allowed for 6-month extensions of marketing rights for new medications in exchange for studying new therapeutics within the pediatric population [10]. This has been a financially successful venture for the estimated median cash inflow totaling \$140 million for these additional 6 months of exclusivity [11]. For those of us who treat patients with pediatric onset disabilities, we have yearned for medications with specific indications to treat the conditions we see in clinic. For many years, pediatric rehabilitation specialists have been required to repurpose medications developed and studied for other reasons (i.e., prednisone or deflazacort for Duchenne muscular dystrophy) or use medications approved for adult-aged patients for pediatric patients (i.e., initially several botulinum toxins for cerebral palsy).

Fortunately, the rate of $R \& D$ focused on the populations treated in this field of pediatric rehabilitation medicine compared to the past 20 years has been evolving at an exponential level. Even in the last 5 years, Botox ${ }^{\circledR}$, Dysport ${ }^{\circledR}$, and Xeomin ${ }^{\circledR}$ all have therapeutic indications for the pediatric population [12-14]. The genomic advances with Spinraza ${ }^{\circledR}$, Evrsydi ${ }^{\circledR}$, Zolgensma ${ }^{\circledR}$, Exondys $51^{\circledR}$ and Vyondys ${ }^{\circledR}$ have changed the potential genotype-phenotype relationship for those being treated. Unfortunately, even more than the awe-inspiring R\&D that it took to bring these medications to market, many were furious with the cost of these medications. Historically in the United States, the trend has been for pharmaceutical companies to perform the R\&D. With the recent investiture in governmental funds towards a COVID-19 vaccine, this may be the turning of the tide toward the United States government investing more into pharmaceutical research and partnering with industry in a symbiotic relationship to improve the health of its citizens.

Despite the recent changes for a select few medications to receive FDA approval and obtain 'labeling' in the pediatric population, approximately $90 \%$ of pediatric-aged patients admitted to an inpatient rehabilitation unit receive medications that are utilized off-label [15]. Furthermore, large differences between prescribing practices, drug clearance and clinical responses exist between pediatric patients with cerebral palsy $[16,17]$. This highlights the need for our specialty to start treating individual patients as individuals by more precisely capturing factors associated with variations in the concentration of the medication in different compartments and, ultimately, in clinical responses [18].

If the government continues to have an interest in increasingly funding pharmaceutical related research, 
the door is open for our specialties and for our patients. Furthermore, we have a duty to systematically evaluate the medications that we give children to ensure we are minimizing adverse events and optimizing outcomes. I, for one, will continue to be at the bedside and working at my research bench to ensure our patients receive the 'right dose of the right medication at the right time for the right patient.' After seeing the government commitment toward vaccine and drug development during COVID-19, I hope they remain engaged partners for development.

\section{Conflict of interest}

The author has no conflicts to report.

\section{References}

[1] Boulware DR, Pullen MF, Bangdiwala AS, Pastick KA, Lofgren SM, Okafor EC, et al. A Randomized Trial of Hydroxychloroquine as Postexposure Prophylaxis for Covid-19. N Engl J Med. 2020; 383(6): 517-25. doi: 10.1056/NEJMoa2016638.

[2] Bull-Otterson L, Gray EB, Budnitz DS, Strosnider HM, Schieber LZ, Courtney J, et al. Hydroxychloroquine and Chloroquine Prescribing Patterns by Provider Specialty Following Initial Reports of Potential Benefit for COVID-19 Treatment - United States, January-June 2020. MMWR Morb Mortal Wkly Rep. 2020; 69(35): 1210-5. doi: 10.15585/mmwr. mm6935a4.

[3] Beigel JH, Tomashek KM, Dodd LE, Mehta AK, Zingman BS, Kalil AC, et al. Remdesivir for the Treatment of Covid-19Final Report. N Engl J Med. 2020 Oct 8; NEJMoa2007764. doi: 10.1056/NEJMoa2007764.

[4] Sheahan TP, Sims AC, Leist SR, Schafer A, Won J, Brown AJ, et al. Comparative therapeutic efficacy of remdesivir and combination lopinavir, ritonavir, and interferon beta against MERSCoV. Nat Commun. 2020; 11(1): 222. doi: 10.1038/s41467019-13940-6.

[5] Agostini ML, Andres EL, Sims AC, Graham RL, Sheahan TP, Lu X, et al. Coronavirus Susceptibility to the Antiviral Remdesivir (GS-5734) Is Mediated by the Viral Polymerase and the Proofreading Exoribonuclease. mBio. 2018 Mar 6; 9(2): e00221-18. doi: 10.1128/mBio.00221-18.
[6] Brown AJ, Won JJ, Graham RL, Dinnon KH, 3rd, Sims AC, Feng JY, et al. Broad spectrum antiviral remdesivir inhibits human endemic and zoonotic deltacoronaviruses with a highly divergent RNA dependent RNA polymerase. Antiviral Res. 2019; 169: 104541. doi: 10.1016/j.antiviral.2019.104541.

[7] Group RC, Horby P, Lim WS, Emberson JR, Mafham M, Bell JL, et al. Dexamethasone in Hospitalized Patients with Covid-19 - Preliminary Report. N Engl J Med. 2020 Jul 17; NEJMoa2021436. doi: 10.1056/NEJMoa2021436.

[8] (ASPA) ASfPA. Fact Sheet: Explaining Operation Warp Speed [updated October 14, 2020; cited 2020 October 16]. Available from: https://www.hhs.gov/coronavirus/explaining-operationwarp-speed/index.html.

[9] Wouters OJ, McKee M, Luyten J. Estimated Research and Development Investment Needed to Bring a New Medicine to Market, 2009-2018. JAMA. 2020; 323(9): 844-53. doi: 10.1001/jama.2020.1166.

[10] Food and Drug Administration Modernization Act of 1997

[11] Li JS, Eisenstein EL, Grabowski HG, Reid ED, Mangum B, Schulman KA, et al. Economic return of clinical trials performed under the pediatric exclusivity program. JAMA. 2007; 297(5): 480-8. doi: 10.1001/jama.297.5.480.

[12] BOTOX (onabotulinumtoxinA) Label - FDA. Available from: https://www.accessdata.fda.gov/drugsatfda_docs/label/2011/ 103000s5236lbl.pdf.

[13] Dysport (abobotulinumtoxinA) [package insert]. Ipsen Biopharmaceuticals. Basking Ridge NJ. [January 6 2017].

[14] Xeomin (Drug Package Insert) [cited 2020 October 19, 2020]. Available from: https://www.accessdata.fda.gov/drugsatfda docs/label/2020/125360s078lbl.pdf.

[15] Luedtke KE, Buck ML. Evaluation of Off-label Prescribing at a Children's Rehabilitation Center. J Pediatr Pharmacol Ther. 2014; 19(4): 296-301. doi: 10.5863/1551-6776-19.4.296.

[16] McLaughlin MJ, Ratnasingam D, McGhee E. Variability of Steady State Oral Baclofen Prescribing Practices in Pediatric Patients With Cerebral Palsy. Am J Phys Med Rehabil. 2020 May; 99(5): 441-443. doi: 10.1097/PHM.0000000000001334.

[17] McLaughlin MJ, He Y, Brunstrom-Hernandez J, Thio LL, Carleton BC, Ross CJD, et al. Pharmacogenomic Variability of Oral Baclofen Clearance and Clinical Response in Children With Cerebral Palsy. PM R. 2018 Mar; 10(3): 235-243. doi: 10.1016/j.pmrj.2017.08.441.

[18] McLaughlin MJ, Wagner J, Shahknovich V, Carleton B, Leeder JS. Considerations for Implementing Precision Therapeutics for Children. Clin Transl Sci. 2019; 12(2): 140-50. doi: 10.1111/cts. 12607 . 